\title{
Conceptualización matemática: un análisis de situaciones-problemas basado en la Teoría de los Campos Conceptuales
}

\author{
Débora Lima Gularte \\ dr.lima00@gmail.com \\ https://orcid.org/0000-0001-9334-4010 \\ Universidade Federal do Rio Grande (FURG) \\ Rio Grande, Brasil. \\ Tanise Paula Novello \\ tanise.novello@ufpel.edu.br \\ https://orcid.org/0000-0002-9585-6893 \\ Universidade Federal de Pelotas (UFPel) \\ Pelotas, Brasil.
}

Recibido: 29/março/2021 Aceptado: 24/agosto/2021

\begin{abstract}
Resumen
A través de las inquietudes y preguntas sobre el aprendizaje matemático, el presente trabajo tiene como objetivo presentar un estudio sobre la conceptualización de las Matemáticas a través de situaciones problemáticas basado en la Teoría de los Campos Conceptuales, de Gérard Vergnaud. Dicha teoría propone estudiar cómo ocurre el aprendizaje de conceptos, es decir, comprender cómo se desarrolla el sistema cognitivo y cómo se aprenden habilidades más complejas. Así, el objetivo de este estudio es investigar a un colectivo de alumnos de $7^{\circ}$ año de Educación Primaria que comprendan los conceptos de la matemática a partir de situaciones problemáticas basadas en la Teoría de Campos Conceptuales (CBT). Para ello, se crearon situaciones problemáticas involucrando ecuaciones de primer grado vinculadas a actividades específicas y contextualizadas que trajeron, además del concepto abordado, la conciencia del consumo de energía eléctrica. Finalmente, se espera que esta investigación sea un punto de partida para una investigación más profunda de la conceptualización matemática, a partir de la Teoría de Campos Conceptuales, que ofrece un aporte enriquecedor para la comprensión del desarrollo y aprendizaje de habilidades.
\end{abstract}

Palabras clave: Aprendizaje matemático. Conceptualización. Situación problemática. Teoría de los campos conceptuales.

\section{Conceitualização matemática: uma análise de situações-problemas fundamentada na Teoria dos Campos Conceituais}

\begin{abstract}
Resumo
Mediante as inquietações e questionamentos acerca do aprendizado matemático, o presente trabalho visa apresentar um estudo sobre a conceitualização da Matemática através de situaçõesproblema fundamentadas na Teoria dos Campos Conceituais, de Gérard Vergnaud. Tal teoria propõe estudar como acontece o aprendizado de conceitos, ou seja, compreender como se desenvolve o sistema cognitivo e como habilidades mais complexas são aprendidas. Assim, o objetivo deste estudo é investigar um coletivo de alunos do $7^{\circ}$ ano do Ensino Fundamental compreendem os conceitos de matemática a partir de situações-problema baseadas na Teoria
\end{abstract}


dos Campos Conceituais (TCC). Para tanto, foram criadas situações-problema envolvendo equações do primeiro grau ligadas a atividades específicas e contextualizadas que trouxeram, além do conceito abordado, a conscientização do consumo de energia elétrica. Por fim, é esperado que esta pesquisa seja um ponto de partida para uma investigação mais aprofundada sobre a conceitualização matemática, partindo da Teoria dos Campos Conceituais, a qual oferece um aporte enriquecedor na compreensão do desenvolvimento e aprendizagem de competências.

Palavras chave: Aprendizagem matemática. Conceitualização. Situação-Problema. Teoria dos Campos Conceituais

\title{
Mathematical conceptualization: an analysis of situations-problems based on the Theory of Conceptual Fields
}

\begin{abstract}
Through the concerns and questions about mathematical learning, the present work aims to present a study on the conceptualization of Mathematics through problem situations based on the Theory of Conceptual Fields, by Gérard Vergnaud. Such theory proposes to study how the learning of concepts happens, that is, to understand how the cognitive system develops and how more complex skills are learned. Thus, the aim of this study is to investigate a collective of students from the 7 th year of elementary school who understand the concepts of mathematics from problem situations based on the Theory of Conceptual Fields (CBT). To this end, problem situations were created involving equations of the first degree linked to specific and contextualized activities that brought, in addition to the concept addressed, awareness of the consumption of electricity. Finally, it is expected that this research will be a starting point for a more in-depth investigation of mathematical conceptualization, starting from the Theory of Conceptual Fields, which offers an enriching contribution to the understanding of the development and learning of skills.
\end{abstract}

Keywords: Mathematical learning. Conceptualization. Problem Situation. Theoryof Conceptual Fields.

\section{Introdução}

A construção do aprender Matemática atualmente é enfrentada pelos alunos como algo chato e difícil em função da forma mecânica de resolução de exercícios. Muito se discute sobre como um aluno compreende e constrói novos conceitos trabalhados nas aulas, ou até mesmo como podemos tratar algum assunto que realmente faça sentido para os alunos. Ao apresentar um novo conceito em sala de aula, é preciso considerar os conhecimentos prévios dos estudantes a fim de que se possa avançar e estabelecer relações entre os conceitos. Com isso, essa pesquisa surge pela inquietação de entender como o estudante constrói novos conceitos matemáticos, assim o objetivo é investigar como um coletivo de alunos do $7^{\circ}$ ano do Ensino Fundamental 
compreendem os conceitos de matemática a partir de situações-problema baseadas na Teoria dos Campos Conceituais (TCC).

Dentre as várias teorias que compreendem o aprender e o processo cognitivo das pessoas, temos a Teoria dos Campos Conceituais, a qual estuda como é construído o conhecimento de um dado conceito. Vergnaud (1993, p. 01) aponta que a finalidade da teoria é "propor uma estrutura que permita compreender as filiações e rupturas entre conhecimentos, em crianças e adolescentes, entendendo-se por 'conhecimentos', tanto as habilidades quanto as informações expressas".

Além da teoria, trataremos sobre a resolução de problemas como forma de conceitualizar a matemática, apresentando argumentos que apontam a resolução de problemas como um forte aliado na aprendizagem desta ciência por ser pautada na contextualização, legitimando o cotidiano e o contexto do aluno. Sendo assim, criou-se situações-problema envolvendo equações do primeiro grau, que trazem a problemática do consumo de energia elétrica como tema transversal.

Com base na Teoria dos Campos Conceituais e na resolução de problemas, desenvolveuse uma proposta pedagógica em uma turma do Ensino Fundamental da rede municipal da cidade do Rio Grande / RS. Esta atividade será o objeto de análise para que se possa começar um estudo aprofundado a fim de obter algumas respostas e encaminhamentos para as inquietações que delimitaram o objetivo deste estudo.

\section{Conceitualização através da resolução de problemas}

De forma geral, expressiva parte dos alunos apresenta questionamentos sobre a aplicabilidade da Matemática em seu cotidiano, de forma que propõem uma discussão aos educadores acerca dos métodos e práticas educacionais que envolvem o ensinar e o aprender Matemática. Temos, ainda corrente, uma prática comum balizada na utilização de fórmulas e técnicas mecanizadas, nas quais o professor propõe um exercício e o aluno reproduz da mesma forma. Essas práticas têm sido problematizadas e questionadas por não terem se mostrado eficazes no ensino, uma vez que não apresentam, de forma clara, uma resposta do aluno, o que os torna meros receptores e reprodutores de técnicas. 
Em vista disso, temos a resolução de problemas como proposta no ensino, tanto na Matemática quanto nas diversas áreas do conhecimento, que possibilita relacionar os conceitos de sala de aula com as experiências diárias do aluno. Esta proposta tem potencial pedagógico por permitir trabalhar partindo da construção do problema inicial ou até mesmo com o resultado, gerando novas conexões e aprendizados. Dante (1989, p. 09) traz a resolução de problemas como sendo "qualquer situação que exija o pensar do indivíduo para solucioná-la". O autor ainda nos apresenta a resolução de problemas com o objetivo de instigar o aluno a pensar de forma produtiva, desenvolvendo o raciocínio e enfrentamento ante situações impostas a eles, que possibilitarão seu envolvimento nas aplicabilidades da Matemática (DANTE, 1989).

Ausubel, Novak e Hanesian (1978, p.472) se referem a resolução de problemas como uma "aprendizagem por descoberta", em que

a solução de problemas refere a qualquer atividade em que tanto a representação cognitiva da experiência passada como os componentes de uma situação problemática atual são reorganizados para atingir um objetivo designado. Tal atividade pode consistir de uma variação mais ou menos apoiada no ensaio e erro de alternativas disponíveis ou de uma tentativa deliberada de formular um princípio ou descobrir um sistema de relações subjacente à solução de um problema (discernimento).

Para esses autores, a resolução de problemas pode ser resolvida por duas abordagens. A primeira é através do ensaio e erro, que "consiste de uma variação, aproximação e correção de respostas aleatória ou sistemática até que uma variante bem sucedida emerja" (AUSUBEL, NOVAK \& HANESIAN, 1978, p.473). Em outras palavras, ela consiste nas tentativas de resolução, entre acertos e erros, até chegar à solução. A segunda abordagem consiste no discernimento que, diferente da primeira, está relacionado à descoberta daquilo que está implícito à solução do problema proposto. Tanto a primeira abordagem quanto a segunda envolvem a criatividade que, por sua vez, é um dos pontos-chave da solução de problemas. Desse modo, conceitos e elementos que já fazem parte do sistema cognitivo da criança auxiliam na descoberta do resultado.

A Base Nacional Comum Curricular (BRASIL, 2017), documento componente da Educação Básica brasileira, propõe a resolução de problemas como uma competência a ser desenvolvida pelos alunos, promovendo a capacidade em aprender, utilizar e compreender a Matemática em diferentes situações. Dessa maneira, percebemos que resolver um problema vai além de algo mecanizado, mas parte de uma construção progressiva do aluno, que o incita a 
buscar respostas, realizar tentativas buscando a solução, além de comparar seus resultados com os colegas, possibilitando a integração e socialização.

Utilizar a resolução de problemas como uma proposta metodológica é uma forma de tornar o aprendizado mais atrativo, facilitando a compreensão de conceitos e métodos matemáticos, refletindo na formação do aluno como parte integrante da sociedade, além de trabalhar de forma imbricada os conteúdos específicos da matemática atrelado as habilidades e competências. Portanto, tentar-se-á analisar como é o processo de desenvolvimento do aluno através do estudo de campos conceituais, no qual será discutido na seção seguinte.

\section{Teoria dos Campos Conceituais}

Buscando atribuir sentido aos pontos abordados na seção anterior, apresentamos a Teoria dos Campos Conceituais (TCC), que busca compreender como se desenvolve o sistema cognitivo e como habilidades mais complexas são aprendidas. O objetivo da teoria é dar suporte explicativo aos estudos realizados sobre as ligações e os rompimentos que a aprendizagem provoca nas pessoas. Sendo assim,

\footnotetext{
a Teoria dos Campos Conceituais é uma teoria cognitivista neopiagetiana que pretende oferecer um referencial mais frutífero do que o piagetiano ao estudo do desenvolvimento cognitivo e da aprendizagem de competências complexas, particularmente aquelas implicadas nas ciências e na técnica, levando em conta os próprios conteúdos do conhecimento e a análise conceitual de seu domínio. (MOREIRA, 2017, p. 65).
}

Um campo conceitual é constituído por quatro elementos base: Conceito, Situação, Esquema e Invariantes Operatórios. O estudo de tal campo tem como objetivo "designar subcampos da experiência, em torno das duas ideias de situação e conceito" (VERGNAUD, 2017, p. 40). Esses subcampos de experiência fazem parte de campos de experiência, compreendendo as vivências do dia a dia, seja familiar, da formação acadêmica e profissional. É através das experiências que pode ser investigado o processo de competências e conceitualizações adquiridas.

A compreensão desse progresso se dá através da análise de situações e conceitos. Tal fato ressalta que "um conceito não se desenvolve numa única categoria de situações, mas dentro 
de uma certa variedade, que pode ser muito grande. Correlativamente, uma situação não se analisa a partir de um conceito apenas, senão de vários" (VERGNAUD, 2017, p. 40).

Diante disso, temos o conceito, constituído por três conjuntos de elementos importantes, que Vergnaud intitula de $C=(S, I, R)$, sendo $S$ as situações que geram lógica ao conceito; $I$ as relações, objetos e propriedades tomadas como ferramentas para que haja domínio das situações que compõem o conjunto $S$; e, por fim, o R são todas as representações simbólicas que ajudam a simbolizar os invariantes operatórios e, por conseguinte, tornar significativas as situações (VERGNAUD, 1993, 2017; MOREIRA, 2017).

Isto posto, apresenta-se a situação, vista como uma tarefa, da qual situações mais difíceis podem ser resolvidas com uma gama de tarefas combinadas. Sendo assim, "os processos cognitivos e as respostas do sujeito são função das situações com as quais é confrontado" (MOREIRA, 2017, p. 72).

Como o sujeito possui o domínio de situações na qual já possui propriedade, consideramos que os conceitos anteriormente abordados nessas situações já fazem sentido para ele. Então, quando o sujeito se depara com novas situações, ele necessita de novos meios para adquirir o domínio do conceito abordado.

A definição de situação nos leva a outro elemento importante: esquema. Este componente diz respeito às habilidades e procedimentos que já são de conhecimento da pessoa, ou seja, os componentes cognitivos já adquiridos por ela. É através do esquema que a conexão entre o sujeito e as situações e seus significantes faz sentido. Ademais, "é nos esquemas que se devem pesquisar os conhecimentos-em-ação do sujeito, isto é, os elementos cognitivos que fazem com que a ação do sujeito seja operatória” (MOREIRA, 2017, p. 74).

Além disso, "um esquema é um universal que é eficiente para toda uma gama de situações e pode gerar diferentes sequências de ação, de coleta de informações e de controle, dependendo das características de cada situação particular" (VERGNAUD, 1998 apud MOREIRA, 2017, p.74) ${ }^{1}$.

Basicamente, o esquema é distinguido em duas classes de situações: na primeira o indivíduo possui competências necessárias para tratar de certa situação; já na segunda, o sujeito não possui as competências para resolver uma determinada situação, o que faz com que ele tenha que dispor de alternativas de resolução, resultando em acertos e erros.

1 Usou-se o 'apud' por falta da obra original de Vergnaud, 1998. 
Neste sentido, a ideia de esquema não age da mesma forma nas duas classes. Isso porque na primeira o sujeito age de forma automática, utilizando métodos de um esquema, porém na segunda classe, ele poderá utilizar um esquema que conhece. No entanto, a situação irá necessitar de outros esquemas que o sujeito ainda não tem, o que resulta na construção e desconstrução de combinações de esquemas.

Diante disso, temos que os esquemas são organizados a partir de uma dada situação, sendo composto por padrões ou implicações. De modo geral, podemos dizer que "o esquema é a forma estrutural da atividade, é a organização invariante do sujeito sobre uma classe de situações dadas e contém conhecimentos-em-ação que são implícitos” (MOREIRA, 2017, p.80). Esses conhecimentos-em-ação se constituem de teoremas-em-ação e conceitos-em-ação, que fazem parte dos Invariantes Operatórios.

Define-se teoremas-em-ação "uma proposição tida como verdadeira sobre o real" (MOREIRA, 2017, p.80). Já o conceito-em-ação "é um objeto, um predicado, ou uma categoria de pensamentos tida como pertinente, relevante" (MOREIRA, 2017, p.80). Sendo assim, podemos dizer que os conceitos são a parte formadora dos teoremas, assim como os teoremas “são propriedades que dão aos conceitos seus conteúdos" (VERGNAUD, 1998 apud MOREIRA, 2017, p.83)². Os conceitos-em-ação e teoremas-em-ação são implícitos, pois além de não serem científicos, a maioria dos alunos não consegue definir ou explicar em palavras seus aprendizados, ou seja, os conceitos e teoremas-em-ação.

Em suma, estudar um campo conceitual requer análise das diversas classes de situações que são impostas aos alunos. Exige também investigar como o aluno utiliza os objetos e representações simbólicas para resolver determinada situação. Assim, para resolver uma situação, necessitamos da ação gerada pelos esquemas através dos invariantes operatórios, para a aquisição de um conceito e consequentemente de um campo conceitual, em que se dará progressivamente.

\section{O método em prática: caracterização da turma e proposta}

Este trabalho trata-se de uma pesquisa exploratória na qual será realizado um estudo de caso acerca do campo conceitual das equações do primeiro grau. A elaboração e prática da proposta pedagógica se idealizou com uma turma do sétimo ano do ensino fundamental da rede

2 Utilizou-se apud novamente por falta da obra original de Vergnaud, 1998. 
Municipal da cidade do Rio Grande/RS. A turma era composta por 30 alunos na faixa etária de 12 a 14 anos de idade, que residem nas imediações da escola.

A proposta foi organizada em quatro encontros e contemplou o conteúdo de Equações do Primeiro Grau, utilizando materiais que os alunos tinham em mãos, como caderno e lápis, além da balança de pratos, que foi levada para a sala de aula para o manuseio dos alunos, e contas de energia elétrica. A balança de pratos foi o material concreto utilizado como auxiliar na noção intuitiva dos alunos sobre as equações do primeiro grau. A conta de energia elétrica foi o mecanismo usado na construção de equações, gerando também a problematização sobre a economia de energia elétrica. Utilizamos, ainda, situações-problema como metodologia, de forma que elementos do dia a dia, como a conta de energia elétrica, auxiliassem a busca do aluno na construção do problema, bem como resolução e discussão de resultados.

\section{Implementando as Equações do Primeiro Grau}

O primeiro encontro iniciou-se através de breve conversa com a turma, por meio do questionamento acerca do que os alunos entendiam por equações do primeiro grau, levando em conta o fato de que eles já haviam desenvolvido o conteúdo anteriormente juntamente com o professor regente. Foram indagadas questões como: “o que é necessário em uma equação?”; “o que é uma incógnita?"; "como resolvemos uma equação?". Partindo disso, foi solicitado que a turma formasse pequenos grupos para interação. Neste momento, foram disponibilizadas as balanças de pratos para que os alunos tivessem o primeiro contato e, em seguida, foram propostos alguns desafios com material concreto, o que facilitou a percepção sobre a ideia de igualdade.

Após esse primeiro momento, foi realizada, juntamente com a turma, a resolução de equações do primeiro grau no quadro negro, e foi solicitado que os alunos ajudassem a encontrar a solução de cada questão. Finalizadas as questões, houve a socialização com a turma e posterior questionamento sobre a aplicação das equações do primeiro grau no dia a dia dos estudantes.

Na sequência, introduziu-se o tema que seria trabalhado no encontro seguinte a partir de algumas perguntas que induziam os alunos a pensar em gastos de energia elétrica nas suas casas, tais como: "Você sabe qual o valor gasto de energia na sua casa?"; "Quais eletrodomésticos vocês acham que consomem mais energia?", "Você sabe calcular estes gastos de energia?". 
Assim, propôs-se uma tarefa de casa que consistia em cada aluno cronometrar e registrar o tempo gasto de banho dos componentes de suas casas e levar para o encontro seguinte.

Desta forma, o segundo encontro foi iniciado recapitulando a tarefa de casa, bem como as atividades anteriormente desenvolvidas. Foi perguntado para os alunos se sabiam como a energia elétrica chegava até suas casas, como ela era produzida e como era calculado o gasto final que chegava até eles através das contas de luz. Partindo dos questionamentos sobre o valor das contas de energia elétrica, os alunos receberam um pequeno texto que explica brevemente como é gerado a energia elétrica e como é feita a distribuição da mesma (Figura 1), possibilitando o início da conversa.

Figura 1 - Texto introdutório sobre energia elétrica

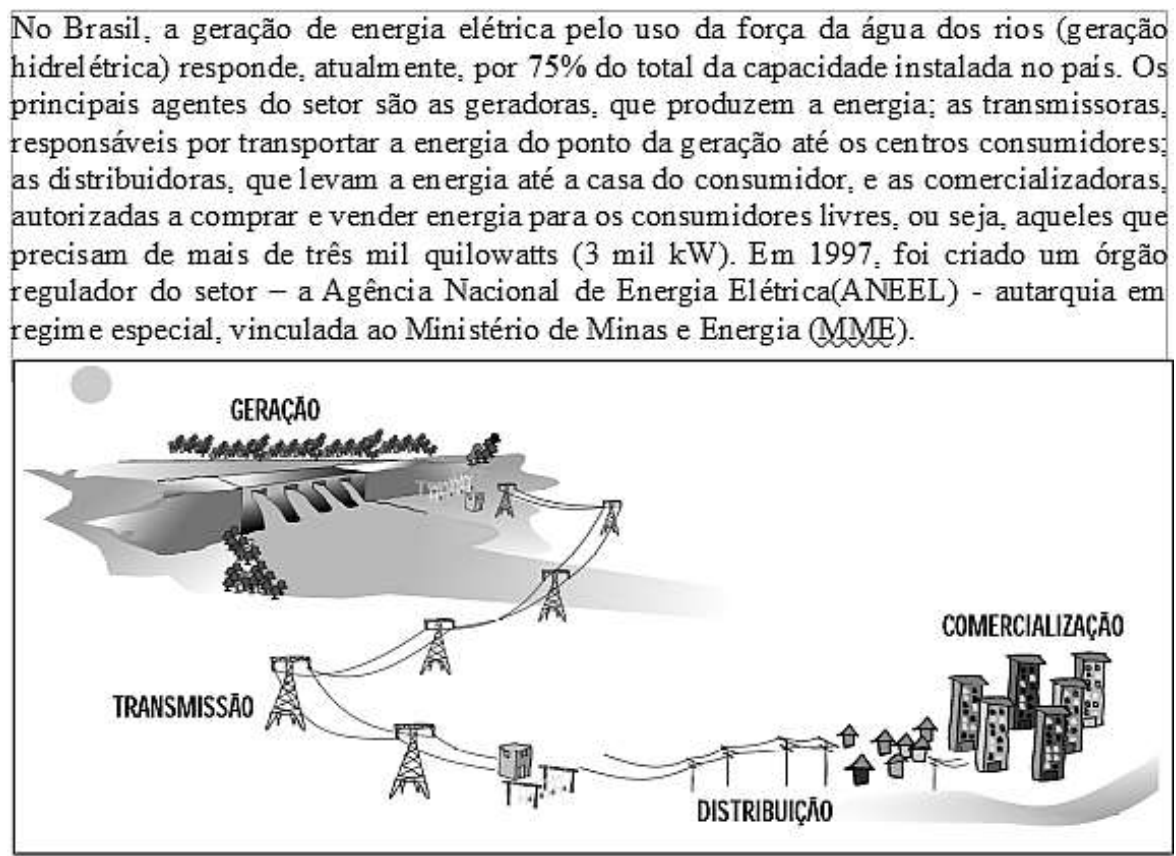

Fonte: Agência Nacional de Energia Elétrica (ANEEL)

Isto posto, explicou-se aos alunos que seriam propostas situações que demandariam atividades específicas sobre o consumo de energia elétrica, a qual era um elemento que todos tinham acesso. Partindo disso, foi proposto a situação 1 (Figura 2), que consistia no questionamento aos alunos acerca do cálculo básico do consumo de energia elétrica na casa de cada um. Em seguida, partindo da situação-problema e utilizando a tarefa deixada para eles no encontro anterior referente ao tempo de banho dos integrantes de suas casas, iniciou-se a atividade, propondo a realização do cálculo correspondente ao gasto diário de energia elétrica.

Figura 2 - Situação 1 proposta aos alunos 


\section{SITUAÇÃO 1: VOCÊ SABE CALCULAR A QUANTIDADE DE ENERGIA QUE GASTAMOS EM CASA?}

Calcular o gasto de energia elétrica do chuveiro com o tempo de banho que você trouxe da sua casa.

Fonte: A autora (2020).

A construção do cálculo partiu do questionamento aos alunos sobre os elementos necessários para a fórmula, além de como poderíamos resolver a questão a partir de métodos que os estudantes tinham conhecimento e facilidade.

Em continuidade ao projeto aplicado, o terceiro encontro foi principiado de formar a recapitular a atividade desenvolvida pelos estudantes no encontro anterior. Então apresentou-se a conta de energia elétrica (Figura 3) e foram explicados os itens importantes como consumo em kwh, o preço cobrado pelas companhias de energia para o fornecimento de luz e os adicionais, como as bandeiras tarifárias.

Figura 3 - Modelo de conta de energia elétrica

\begin{tabular}{|c|c|c|c|c|c|}
\hline \multicolumn{3}{|c|}{$\begin{array}{l}\text { Rio Grande - RS } \\
\text { CPF: } 95711600087 \\
\text { Classe de Consumo Aneel: RESIDENCIAL - Residencial }\end{array}$} & \multicolumn{3}{|c|}{ Bandeira Vigente: Bandeira Vermelha } \\
\hline \multirow{3}{*}{$\begin{array}{l}\text { Mediçảo } \\
\text { No do medidor } \\
\text { Fator de Multiplicaçă̄o } \\
\text { Leitura 09/0B/2019 } \\
\text { Leitura } 10 / 07 / 2019 \\
\text { Consumo* }\end{array}$} & \multirow{2}{*}{$\begin{array}{l}\text { Consumo } \\
133 \mathrm{kWh}\end{array}$} & \multirow{2}{*}{$\begin{array}{l}\text { Faturamento } \\
08 / 2019\end{array}$} & \multirow{2}{*}{\multicolumn{2}{|c|}{$\begin{array}{l}\text { Vencimento } \\
05 / 09 / 2019\end{array}$}} & \multirow{2}{*}{$\begin{array}{c}\text { Total em Reais } \\
113,17\end{array}$} \\
\hline & & & & & \\
\hline & Descriçăo & & lade & Preço & Valor R\$ \\
\hline •Consuma Lida & $\begin{array}{l}\text { Consumo } \\
\text { Adic Band. Amarela } \\
\text { Adic Band. Vermel P1 } \\
\text { Subtotal (R\$) }\end{array}$ & & 133 & 0,817519 & $\begin{array}{r}108,73 \\
2,07 \\
2,37 \\
113,17\end{array}$ \\
\hline 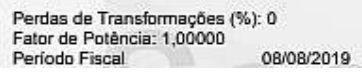 & & & & $=$ & 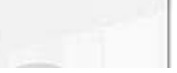 \\
\hline
\end{tabular}

Fonte: Companhia Estadual de Energia Elétrica (CEEE).

Após esclarecer algumas dúvidas sobre a conta de energia e as bandeiras tarifárias, apresentou-se a situação 2 (Figura 4) através do questionamento sobre o cálculo do gasto de um eletrodoméstico de forma mensal. Então a atividade foi construída partindo da situação 1, calculando o gasto mensal de energia elétrica referente ao consumo do chuveiro elétrico. Os estudantes utilizaram as contas realizadas por eles no encontro anterior, ajustando e conversando sobre como poderia ser executado o cálculo. 
Figura 4 - Situação 2 proposta aos alunos

SITUAÇÃO 2: AGORA NÓS SABEMOS QUE PARA CALCULAR A QUANTIDADE DE ENERGIA GASTA DE CERTO ELETRODOMÉSTICO, É PRECISO MULTIPLICAR A POTÊNCIA DELE PELO TEMPO DE USO DIÁRIO E DIVIDIR POR 1000. MAS E SE GOSTARÍAMOS DE CALCULAR O GASTO MENSAL DESTE ELETRODOMÉSTICO E QUAL O VALOR EM REAIS QUE PAGAREMOS NA CONTA DE LUZ? Utilizando a situação 1, calcule o valor que será pago pelo tempo de banho no período de 30 dias.

Fonte: A autora (2020).

No quarto e último encontro, foi recapitulado as situações desenvolvidas anteriormente. Diante disso, a situação 3 (Figura 5) foi alvitrada como fechamento da proposta de modo que englobasse as atividades precedentes. A situação consistia em descobrir o consumo de energia elétrica dos demais eletrodomésticos que os alunos conheciam e tinham em suas casas.

Figura 5 - Situação 3 proposta aos alunos

SITUAÇÃO 3: JÁ SABEMOS COMO CALCULAR A QUANTIDADE DE ENERGIA ELÉTRICA
GASTA PELO CHUVEIRO, BEM COMO O VALOR QUE PAGAMOS NA CONTA DE LUZ. AGORA
VAMOS CALCULAR A ENERGIA GASTA DE ALGUNS ELETRODOMÉSTICOS QUE TEMOS EM
CASA?

Através da ficha técnica em mãos, calcule a energia elétrica gasta pelo eletrodoméstico e o valor que será pago na conta de luz.

Fonte: A autora (2020).

Para tanto, distribuiu-se fichas técnicas que continham eletrodomésticos e possuíam também as seguintes informações: potência, tempo de funcionamento em horas e dias, quantidade de eletrodomésticos. Elas foram os instrumentos auxiliares para a realização da terceira situação (Figura 5), que serviu de fechamento da proposta.

O objetivo da atividade em questão era calcular a quantidade de energia elétrica consumida pelo eletrodoméstico que receberam e, consequentemente, o valor que pagariam ao final do mês na conta de luz. Para o fechamento da atividade, discutiu-se com a turma a respeito do aprendizado através da proposta no que se referia as equações do primeiro grau, mas principalmente sobre o consumo consciente de energia elétrica.

\section{Analisando e discutindo os resultados: uma visão dos registros com base na teoria dos campos conceituais}

Nesta seção, será analisada a proposta através dos elementos da Teoria dos Campos Conceituais (TCC), ou seja, serão identificados os conceitos, situações, esquemas e invariantes 
operatórios presentes nas situações-problema e atividades realizadas pelos estudantes, o que permitirá analisar os elementos mais recorrentes. A Teoria dos Campos Conceituais nos propõe analisar a construção de conceitos através de conexões com situações, possibilitando a conceitualização. Isto posto, serão utilizadas estas relações para verificar os elementos da Teoria dos Campos Conceituais presentes nas situações-problemas atreladas às respectivas atividades.

\section{Conceito}

O Conceito, definido por Vergnaud, pode ser entendido como um conjunto de vários outros conceitos, produzindo uma estrutura de conhecimento. Sendo assim, podemos dizer que são as situações que dão sentido e significado para a formação de um conceito.

O conceito é apresentado como um tripleto de conjuntos composto pelas situações que tornam o conceito significativo. Sendo assim, convém examinar as situações sob a ótica do conceito a partir do tripleto (S, I, R), investigando as situações-problema e verificando os elementos-chave da construção do conceito. $\mathrm{Na}$ análise realizada nas resoluções das situaçõesproblema feitas pelos alunos, destacou-se os conceitos desenvolvidos por eles que estão visíveis, além de outros que estão presentes de forma implícita (Figura 6).

Figura 6 - Conceitos desenvolvidos nas situações-problema

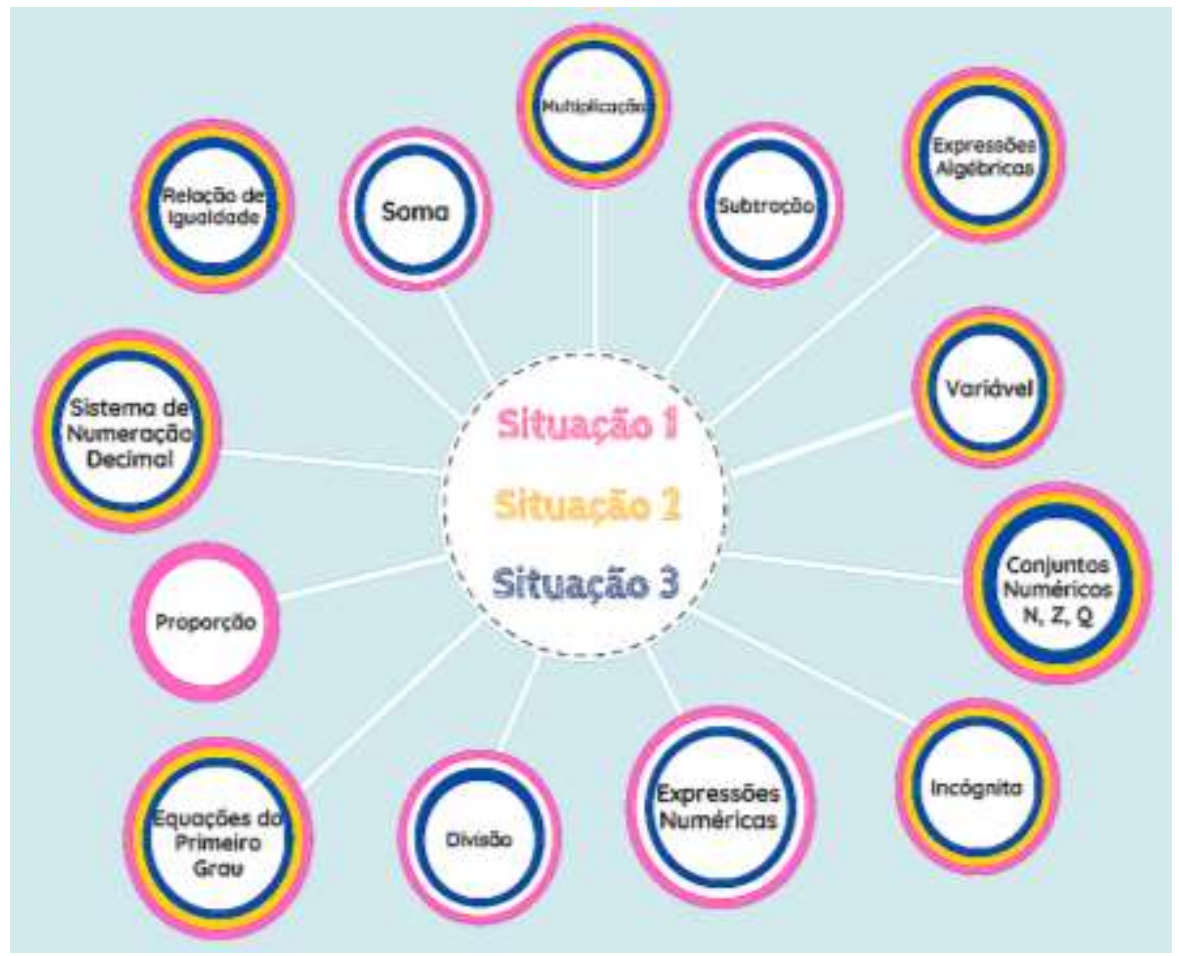


Fonte: A autora (2020).

Com o exposto na Figura 6, buscou-se alguns conceitos executados por eles, analisando o desenvolvimento das situações e atividades. No que se refere às situações 1 e 2 , propôs-se construir o cálculo do consumo de energia elétrica e, para isso, foi solicitado aos alunos que obtivessem o tempo gasto de banho dos componentes de suas casas. Em seguida, explicou-se os elementos necessários para que fosse feito este cálculo que consistia no tempo em horas e a potência em Watts do chuveiro.

Percebemos, através da análise da resolução das situações propostas (Figura 7), que elas possuem alguns conceitos desenvolvidos pelos estudantes, tais como: o próprio conceito de equações do primeiro grau; soma; multiplicação; divisão; subtração; números racionais, decimais, frações, entre outros. Observou-se também que os estudantes se atentaram a encontrar $o$ valor da incógnita ' $x$ ', apesar da dificuldade dos alunos quando foi necessário transformar o tempo do banho de minutos para horas, pois não lembravam como era realizada a transformação.

Figura 7 - Resolução das situações 1, 2 e 3 pelos alunos

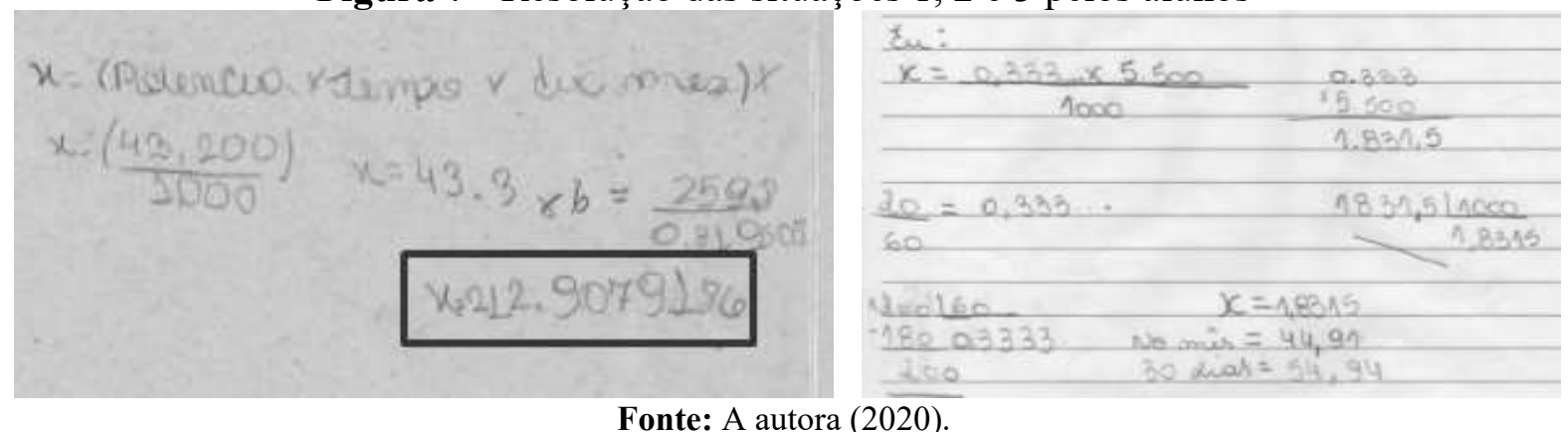

Além disso, por se tratar das equações do primeiro grau, as representações têm um papel de grande importância, pois trazem as letras, os símbolos de operações, além da própria relação de igualdade (VERGNAUD, 2000). Um exemplo seria a Figura 8, na qual o estudante utilizou da relação de "Potência-1600", "Hora-1" e "Dia-15" a fim de esquematizar as ideias para a resolução do problema em que estava trabalhando. Ademais, grande parte dos educandos utilizou os símbolos algébricos e a relação de igualdade como objetos de representação.

Figura 8 - Resolução de situação-problema por um aluno 

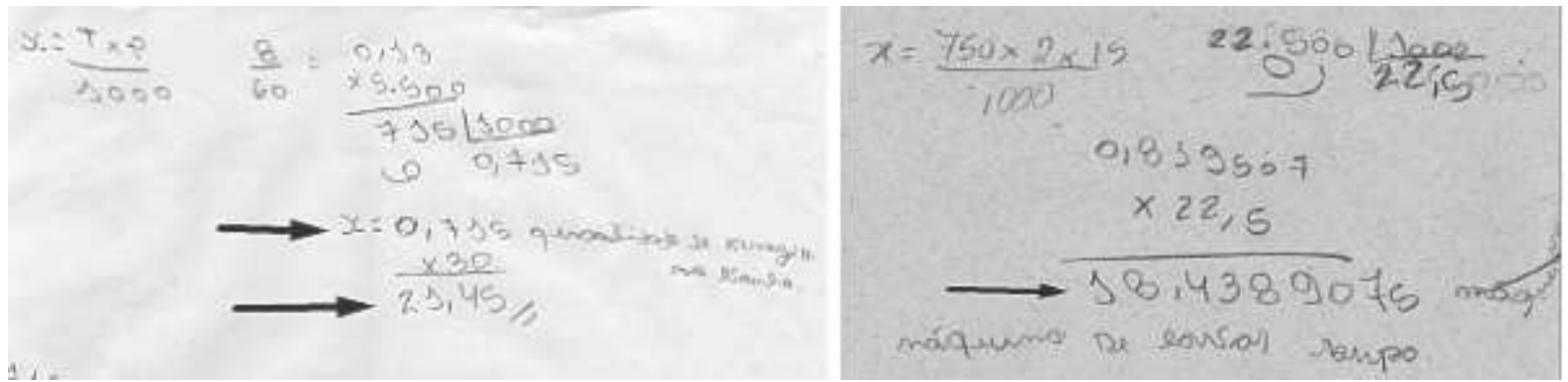

Fonte: A autora (2020).

Cedran e Kiouranis (2019, p. 68) nos permitem concluir que "um conceito trata-se, portanto, do ato de enfrentar as situações, provocar os invariantes e representar as situações e conceitos nela envolvidos". Desta forma, necessitamos analisar a proposta desenvolvida com um olhar no que Vergnaud(1985, 1993, 2008, 2017) chama de Situação.

\section{Situação}

No que refere as situações, podemos observar na Figura 9 que tanto na primeira figura (realizando o cálculo do consumo de energia elétrica através do chuveiro) quanto na segunda figura (executando o cálculo do consumo de eletrodomésticos conhecidos), que os estudantes necessitaram invocar uma ampla variedade de conceitos: divisão, multiplicação, números racionais, entre outros. Assim, por este aspecto, é possível compreender quando Vergnaud(1985, 1993, 2017) nos afirma que uma dada situação apela para diversos conceitos.

Figura 9 - Situações 1, 2 e 3 da proposta desenvolvida

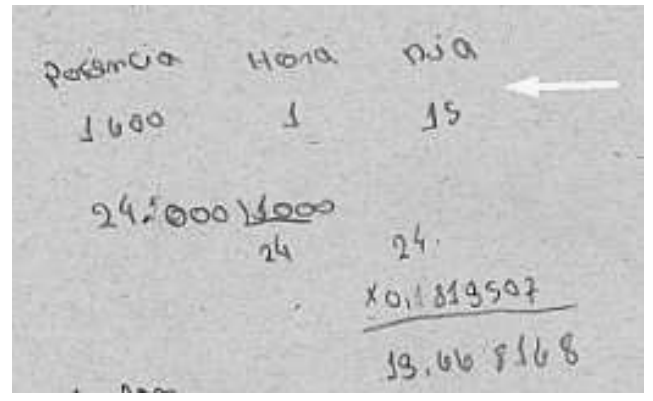

Fonte: A autora (2020).

Porém, para compreender uma situação é preciso analisar os esquemas que o sujeito precisa utilizar. Vergnaud (2001, p. 06) ainda diz que 
é as situações que o esquema se adapta, e um esquema constituído e estabilizado pode ser considerado como uma forma invariante de organização da atividade para uma dada classe de situações. Logo, é o par situação-esquema que está no centro do processo de construção, ou ainda, de apropriação das competências e conhecimentos.

Sendo assim, é através dos esquemas que as situações são organizadas e isto será abordado na próxima seção.

\section{Esquema}

Para Cedran e Kiouranis (2019, p. 69), “os esquemas são uma forma de organização do pensamento e são utilizados para compreender o real, bem como agir sobre ele". O esquema é formado por quatro elementos (VERGNAUD, 1985, 1993, 2000, 2001, 2002a, 2002b, 2008, 2017; CEDRAN e KIOURANIS, 2019): (1) os objetivos, que são responsáveis pela intenção e motivação dos esquemas e organizam a ação; (2) as regras para gerar ação, que são condicionadas aos objetivos e é a parte generativa do esquema, responsável pela tomada de decisões e busca da informação e, sendo assim, não especificamente para gerar ação; (3) os invariantes operatórios, que são: conceitos-em-ação e teoremas-em-ação, construídos no decorrer do tempo; e (4) as possibilidades de inferência.

Frente a isso, no que se refere às equações do primeiro grau, especificamente às situações trabalhadas, temos alguns conhecimentos percebidos à primeira vista como subtração, multiplicação, divisão, a questão da igualdade, e equivalências. Porém, expressiva parcela dos conhecimentos estão implícitos, de modo que os estudantes realizam as atividades através de esquemas que eles já obtiveram o domínio anteriormente. No que concerne à organização das situações-problema e da álgebra no geral, Vergnaud (2000, p. 6) destaca que

\footnotetext{
requer vários tipos de atividades: a elaboração da equação, a resolução das equações, a interpretação das soluções, etc. Cada uma destas atividades requer várias formas de organização da atividade, que se enriquecem e se complexificam durante a aprendizagem. Estas formas são os esquemas.
}

Através das situações desenvolvidas pelos estudantes, notou-se a presença de alguns esquemas: na Figura 10, temos cinco partes separadas pela autora para uma melhor observação. Na primeira parte, observamos que o aluno traçou o caminho a ser percorrido para chegar ao resultado, ou seja, o objetivo que ele tinha era encontrar a solução do problema partindo da 
equação. Aqui também podemos destacar que o aluno se empenhou na busca das informações necessárias para o desenvolvimento da equação que ele criou.

Dados os meios, nas partes 2, 3 e 4 intervieram os invariantes operatórios, desenvolvendo os teoremas-em-ação e os conceitos-em-ação que os alunos já tinham conhecimento. Em relação às possibilidades de inferência, “dificilmente uma ação é realizada sem a saída de novas informações" (CEDRAN; KIOURANIS, 2019, p. 75) ${ }^{3}$. Logo, os processos realizados na resolução da situação da figura 10 possibilitaram que o aluno obtivesse informações como o gasto mensal de energia elétrica do eletrodoméstico, a quantidade de Kwh utilizado por esse eletrodoméstico, a questão do consumo consciente da energia, pois quanto maior a utilização, maior o gasto, entre outras inferências recorrentes das situações 1, 2 e 3 .

Figura 10 - Resolução da situação-problema por aluno

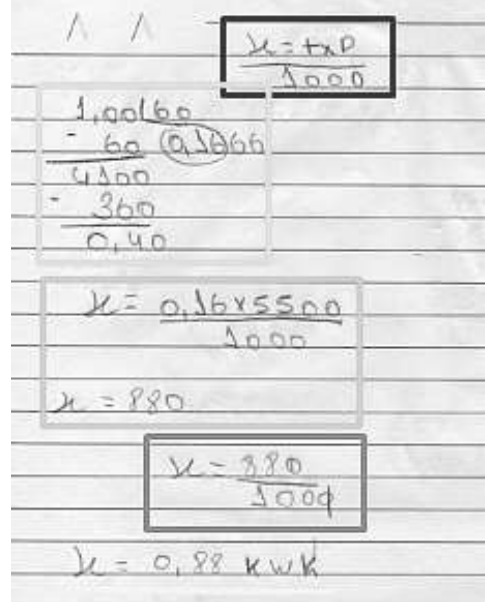

Fonte: A autora (2020).

Vergnaud (2001, p. 7) ainda enfatiza que "o esquema é um universal, já que ele se refere a uma classe de situações e que ele ocasiona uma classe de condutas diferentes, adaptadas às situações particulares encontradas. O que é invariante é a organização, não a atividade”. Logo, é indispensável falarmos sobre um elemento de grande importância dentro do esquema: os invariantes operatórios, pois são eles que reportam os conceitos e teoremas-em-ação necessários para formação dos objetivos, delineando as regras de ação e as decisões a serem tomadas para alcançá-los.

3VERGNAUD, G. a ¿En qué sentido la Teoría de los Campos Conceptuales puede ayudarnos para facilitar aprendizaje significativo? Investigações em Ensino de Ciências, v. 12, n. 2, p. 285-302, 2007. 


\section{Invariantes Operatórios}

Como visto nas seções anteriores, não há como falar de conceito, situação e esquema sem tratar de um elemento importante da conceitualização: os invariantes operatórios. Vergnaud (1985, p. 9) aponta que

se a função última da representação é a conceitualização do real para uma ação eficaz, então os invariantes operatórios, isto é, os objetos, propriedades, relações e processos que o pensamento recorta no real para organizar a ação, constituem o núcleo duro da representação, aquele sem o qual nem as inferências, nem as regras de ação, nem as predições, nem os significantes têm sentido (Destaque do autor).

Diante disto, os invariantes operatórios são constituídos por conceitos e teoremas-emação. Um conceito-em-ação pode ser entendido como um objeto ou predicado, e não nos possibilita obter inferência, pois não são questionáveis. Os teoremas-em-ação, por sua vez, são proposições sobre o real e são tidas como verdadeiras, de modo que pode ser feita inferência acerca da realidade (VERGNAUD, 1985, 1993, 2000, 2001, 2002a, 2002b, 2008, 2017; CEDRAN e KIOURANIS, 2019).

Sendo assim, destacou-se alguns invariantes observados nas resoluções dos problemas desenvolvidos pelos alunos. Na parte 2 (Figura 11), percebemos que o esquema da divisão desenvolve alguns teoremas-em-ação: repartir em uma certa quantidade em partes iguais, 2750$2750=0$, regras de sinais.

Figura 11 - Resolução de situação-problema pelo aluno

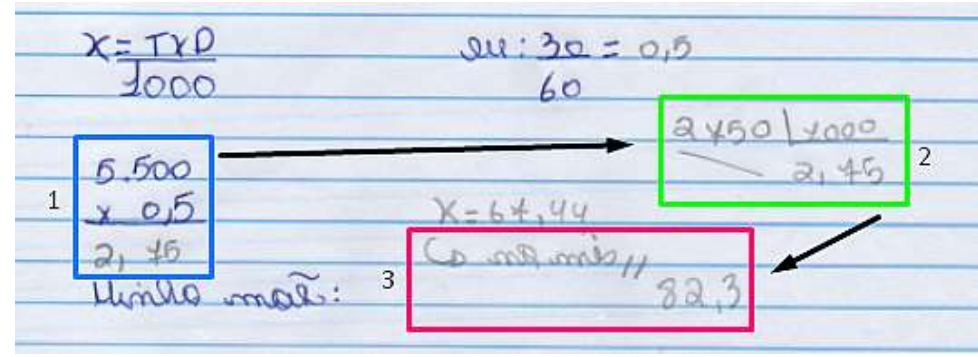

Fonte: A autora (2020).

Entre a parte 1 e 3 (Figura 11), vemos que o estudante utilizou um "teorema-em-ação", ou seja, para chegar ao resultado, ele utilizou-se da multiplicação direta, sabendo que se o eletrodoméstico foi utilizado durante 30 dias, fez-se 1 dia de consumo multiplicado por 30, que é o total de dias contabilizado no mês. 
Ademais, após discutir a proposta sob a ótica de cada elemento da Teoria dos Campos Conceituais, faz-se necessário um fechamento abordando a compreensão deste estudo como um todo.

\section{Uma percepção de modo geral}

Podemos destacar alguns pontos da análise: no que se refere ao conceito, as situações desenvolveram o tripleto $(\mathrm{S}, \mathrm{I}, \mathrm{R})$ do conceito, propondo situações que permitiram identificar os objetos, propriedades e relações que os invariantes operacionais conjuram e que oportunizaram expor algumas representações. As resoluções dos estudantes apontaram vários conceitos que eles já possuíam certo domínio, como as quatro operações fundamentais, por exemplo.

Refletindo acerca da proposta como um todo, percebeu-se uma parte dos alunos não conseguiu compreender o resultado de seus cálculos no final da proposta. Poucos alunos conseguiram expressar a sequência de cálculos que realizaram para saber a quantidade de energia elétrica consumida pelo eletrodoméstico recebido da ficha técnica dos eletrodomésticos da situação 3 .

Em resumo, é possível depreender que o campo conceitual das equações está sendo constituído pelos alunos. Com o decorrer do tempo e com as situações que serão impostas em outros momentos, serão despertados os esquemas que eles desenvolveram nas atividades realizadas, que darão continuidade e provocarão rupturas para, então, construir um novo conhecimento sustentado nos conhecimentos prévios.

\section{Considerações finais}

No decorrer dos últimos anos, vêm sendo levantadas discussões a respeito do aprendizado dos alunos e quais aportes podem auxiliar nesse desenvolvimento. Dentre diversos meios, a resolução de problemas tem se feito bastante recorrente e utilizada pelos educadores como subsídio no ensinar matemática. Porém, também é preciso compreender como utilizar a situação-problema de forma que o conteúdo trabalhado seja compreendido e o aluno consiga construir seu conhecimento e atribuir significado aos conceitos matemáticos estudados. 
Em vista disso, esta pesquisa buscou investigar como é construída a conceitualização matemática pelo aluno, através de situações-problema fundamentadas na Teoria dos Campos Conceituais. Dessa maneira, foram elaboradas situações-problema sobre equações do primeiro grau como proposta pedagógica, de modo que a Teoria dos Campos Conceituais foi a base para a análise.

No desenvolvimento desta pesquisa, pode-se estudar como o aluno aprende um conceito a partir de situações propostas. Este estudo foi possível em virtude dos elementos que a TCC propõe, uma vez que viabiliza examinar as resoluções dos alunos. Porém, destaca-se que, devido à insuficiência no tocante ao tempo de estudo na realização de um trabalho de conclusão de curso, não foi possível explorar minuciosamente cada elemento da TCC aplicado nas situaçõesproblema da proposta.

De modo geral, pode ser percebido que muitos conceitos são despertados em uma dada situação, bem como são despertados esquemas e invariantes operatórios presentes no sistema cognitivo dos estudantes. Ademais, não podemos afirmar que o campo conceitual das equações do primeiro grau foi aprendido ou dominado pelos estudantes, pois o próprio Gérard Vergnaud(1985, 1993, 2000, 2001, 2002a, 2002b, 2008, 2017) nos fala que a aquisição de um campo conceitual pode levar algum tempo mediante a proposição de diversos conceitos, situações, representações, esquemas e invariantes.

Esta pesquisa abordou o estudo da Teoria dos Campos Conceituais no que diz respeito a conceitualização matemática, voltada às Equações do Primeiro Grau, através de situaçãoproblema, e foi possível perceber que não há trabalhos no idioma português que estudem a área da álgebra. Sendo assim, este estudo sugere investigações aprofundadas sobre a conceitualização das equações, bem como do campo da álgebra de modo geral, fundamentadas nos elementos que a TCC nos remete, a qual possibilitará compreender o aprendizado dos estudantes, bem como auxiliar o professor na organização e planejamento das aulas.

O ensinar Matemática é uma tarefa desafiadora para os educadores em se tratando de como os conteúdos podem ser trabalhos em sala de aula para que o aluno tenha proveito das mediações realizadas pelo professor ao apresentar um novo conteúdo. Neste sentido, este estudo buscou compreender a aquisição de um dado conceito da área da Matemática considerando os conhecimentos dos próprios alunos. Além disso, possibilitou realizar reflexões no que se refere a prática docente, dentre desafios e dificuldades encontrados no percurso do "ser professor". Por 
fim, é esperado que esta pesquisa seja um ponto de partida para uma investigação mais aprofundada sobre a conceitualização matemática partindo da Teoria dos Campos Conceituais, a qual oferece um aporte enriquecedor na compreensão do desenvolvimento e aprendizagem de competências.

\section{Referências}

AGÊNCIA NACIONAL DE ENERGIA ELÉTRICA. Por dentro da conta de luz: informação de utilidade pública. 7. ed. Brasília: ANEEL, 2016. Disponível em: https://www.aneel.gov.br/documents/656877/14913578/Por+dentro+da+conta+de+luz/ 9b8bd858-809d-478d-b4c4-42ae2e10b514. Acesso em: 28 Out. 2020

AUSUBEL, D. P.; NOVAK, J. D.; HANESIAN, H. Psicologia Educacional. 2. ed. Rio de Janeiro - RJ: Interamericana, 1978.

BRASIL. Base Nacional Comum Curricular. Brasília: MEC/SEF, 2017. Disponível em: http://basenacionalcomum.mec.gov.br/abase. Acesso em: 30 Out. 2020

CEDRAN, D. P.; KIOURANIS, N. M. M. Teoria dos Campos Conceituais: visitando seus principais fundamentos e perspectivas para o ensino de ciências. ACTIO: Docência em Ciências, v. 4, n. 1, p. 63-86, 2019. Disponível em: https://periodicos.utfpr.edu.br/actio/article/view/7709. Acesso em: 30 Out. 2020 . DOI: $\underline{10.3895 / \text { actio.v4n1.7709 }}$

DANTE, L. R. Didática da resolução de problemas de matemática $1^{\text {a }}$ a $5^{\text {a }}$ séries: para estudantes do curso de magistério e professores do $1^{\circ}$ grau. 3. ed. São Paulo: Ática, 1989.

MOREIRA, M. A. O Iceberg da conceitualização: Teoria dos Campos Conceituais de Vergnaud, o Ensino de Ciências e a Pesquisa nesta área. In GROSSI, E. P. (Org.). O que é aprender? O Iceberg da Contextualização. Porto Alegre: GEEMPA, 2017.

VERGNAUD, G.Conceitos e esquemas em uma teoria operatória da representação. 1985. Disponível em: https:/vergnaudbrasil.com/wp-content/uploads/2020/09/2.1.CONCEITOS-E-ESQUEMAS-EM-UMA-TEORIA-OPERATORIA-DAREPRESENTAC\%CC\%A7A\%CC\%83O.pdf. Acesso em: 05 Nov. 2020.

VERGNAUD, G. Teoria dos campos conceituais. In NASSER, L. (Ed.). Comunicação apresentada em $1^{\circ}$ Seminário Internacional de Educação Matemática do Rio de Janeiro (pp. 1-26). Rio de Janeiro: [s.n], 1993.

VERGNAUD, G. A respeito de frege. 2000. Disponível em: https://vergnaudbrasil.com/wpcontent/uploads/2020/09/2.3.-A-RESPEITO-DE-FREGE.pdf. Acesso em: 30 Out. 2020.

VERGNAUD, G. Construtivismo e a aprendizagem da matemática. 2001. Disponível em:https://vergnaudbrasil.com/wp-content/uploads/2020/09/4.4.CONSTRUTIVISMO-E-APRENDIZAGEM-DA-MATEMA\%CC\%81TICA.pdf. Acesso em: 04 Out. 2020.

VERGNAUD, G. A explicação é algo diferente da conceitualização?. 2002a. Disponível em: https://vergnaudbrasil.com/wp-content/uploads/2020/09/2.5.-A- 
EXPLICAC $\% \mathrm{CC} \% \mathrm{~A} 7 \mathrm{~A} \% \mathrm{CC} \% 83 \mathrm{O}-\mathrm{E}-\mathrm{ALGO}-\mathrm{DIFERENTE-DA-}$ CONCEITUALIZAC\%CC\%A7A\%CC\%83O.pdf. Acesso em: 28 Out. 2020.

VERGNAUD, G. A incorporação dos professores na teoria dos campos conceituais. 2002 b. Disponível em: https://vergnaudbrasil.com/wp-content/uploads/2020/09/4.5.-AINCORPORAC $\% \mathrm{CC} \% \mathrm{~A} 7 \mathrm{~A} \% \mathrm{CC} \% 83 \mathrm{O}-\mathrm{DOS}-\mathrm{PROFESSORES-NA-TEORIA-DOS-}$ CAMPOS-CONCEITUAIS.pdf. Acesso em: 29 Out. 2020.

VERGNAUD, G. Da didática das disciplinas à didática profissional, nada mais que um passo. 2008. Disponível em: https://vergnaudbrasil.com/wpcontent/uploads/2020/09/4.6.-DA-DIDATICA -DAS-DISCIPLINAS-A-DIDATICAPROFISSIONAL-NADA-MAIS-QUE-UM-PASSO.pdf. Acesso em: 04 Out. 2020.

VERGNAUD, G. O que é aprender? Por que a teoria dos campos conceituais? In GROSSI, E. P. (Org.). O que é aprender? O Iceberg da Conceitualização. Porto Alegre: GEEMPA, 2017.

Autores

Débora Lima Gularte Universidade Federal do Rio Grande - FURG

Graduação - Matemática Ensino de Matemática dr.lima00@gmail.com

Tanise Paula Novello Universidade Federal de Pelotas Ensino de matemática, formação de professores, tecnologias na educação. Possui graduação em Licenciatura em Matemática pela Universidade Federal do Rio Grande (2001) mestrado em Educação Ambiental pela Universidade Federal do Rio Grande (2006) e doutorado em Educação Ambiental pela mesma Instituição (2011). Também é professora da FURG vinculada ao Instituto de Matemática, Estatística e Física (IMEF) e membro da Secretaria de Educação a Distância (SEaD) atuando junto a formação de professores e tutores.É professora junto ao Programa de Pós-graduação em Educação em Ciências (PPGEC). Atuando principalmente nos seguintes temas: formação de professores, educação a distância e educação matemática. tanisenovello@,hotmail.com 